\title{
Multicultural Education in USA: Place of Ethnic Minorities
}

\author{
DICKO Abdourahamane \\ Department of Sociology, Wuhan University \\ Wuhan 430072, China \\ E-mail: dabdourahamanedicko772@gmail.com
}

\begin{abstract}
It has become more obviously about the trends of the United States public schools's diversification and the trends have led to the "figure crisis" which calls out to the effective education of minority students. Consequently a new field named Multicultural Teacher Education has been constructed by combining education and multicultural education. As to pursure the multicultural teacher education's balance between theory and practice, the essay illustrates the way of attachment methods, field experience, service learning and actuality, besides the principle of practice on the multi-cultural background.
\end{abstract}

Keywords: USA, Multicultural Teacher Education, Schoolteachers, Practice

\section{Forms of crisis in American Society}

In the United States, the number of students from different linguistic, ethnic, cultural and social background continued to grow. And figure crisis which is consist of the statistics about professionals and learners in the field of education focus on three points

\subsection{Diversity of educational system}

According to statistics from NCES in1998, minority students is near $38 \%$ in the K-12 public school, and the AERA's Division K Newsletter shows that the number of public school including colored races is expect to increase from $33 \%$ at the beginning of the 20 th century to $40 \%$ in $2020,50 \%$ in 2035 , moreover, the $47 \%$ of the total number of the nation's population will be consist by colored races in 2050 on the basis of the estimate by the US Census Bureau in 2000. In addition, according to Collnick and Chinn's viewpoint (2004), close to half of students are minority at K-12 public schools by 2020, and currently more than half of students are people of color in California, the District of Columbia, Mississippi, New Mexico, New York, Texas.

\subsection{Analysis about the education team}

At present, nearly $84 \%$ of education team are white, closely $90 \%$ among teachers working in public school, $75 \%$ middle-class persons whom most of lived in the suburbs, origined in low and middle families or lived in the middle of community to get along with similar people. They get high-education and have single language, but they lack of inter-ethnic communication and cross-cultural competence.

1.3 Differences of educational opportunities, resources and accessing to scholastic achievement between different ethnic and socio-economic groups

Silite shows that most of buckra teachers are empty to knowledge and experience about minority races and students from different culture, and the discrimilation about races, genda, social station and discrepancy in school restrict the educational opportunities of the marginalized populations in the transcultural exchanges. Poverties and black men grin and bear low- expectations and ignoring. It can be finded minority and low-income students and white men, middle school students and education gap in any way.

Crisis is made of the sharp cleavage numbers, structural inequalities and uncoordination between teachers and students, that cause the academic inequality among black man, low-salary students, white man and bourgeois. In classroom, numbers will transform social and cultural gap between teachers and students which will reduce the possibilities of the most prospective teachers learning different cultures in order to understand other peoples knowledge well, and defiance manners to children's different cultures will form. In that case education actions and social reletions will limit the low-income and minority students's learning opportunities, for that reason we must effectively instruct them. Therefore, school, administrators, teachers and educational researcher is always seeking a solution to the problem.

The socio-cultural education's crisis, as Bush said in bill of No Child Left Behind that our nation is gradually divided into two countries, which one is that citizen has the ability of reading and the mind of ideals and the 
other is not. If a country can not afford the duty to educate every child, other areas of education will not succeed. For these reasons that it is necessary to create equal educational opportunities for students from different races, ethnic group, social station and inter-cultural group, to help all students grasp knowledge, attitude and skills in meeting the cross-cultural communication's demands and to create a common civic and moral interests of society eventually which is the ultimate objective of education, while teachers are the key factor of it.

It contains two points in the socio-cultural education's enlightenment: the first is that teachers need to have sufficient cultural sensitivity to treat more fairly to students from different cultural backgrounds and to assume more instructional responsibility for gradually diverse population, and the other is that design suitable curriculum, teaching materials, teaching methods to cultivate teachers' ability to face students of different races, different nationalities, different cultural backgrounds.

How to achieve the goals? In recent 30 years, scholars with a common interests and expertises in the field of academic study including teachers education and muti-culture education also think that education should combine with it and form a new field named multicultural teacher education (MCTE), which goal is trying to make teachers to get multi-cultural foundation by learning more skills and methods. Early 70's, American Association of University Teacher Education suggest that all educators should pool the wisdom of the masses to prepare to teach multi-cultural diversity students in the future. In 1977, an acceptable diversity standards for teacher training was made and it claimed teachers to receive training in an increasingly multi-cultural nature of the challenges of racism and ethnic pluralism. In addition, NCATE (1997) formulate a rule which request all teachers to accept some multicultural curriculum and training. And the curriculum and training are incorporated into a compulsory subject in College of Education, therefore pre-service teachers not only familiar with the cultural diversity but also the exchanges between students from different cultural backgrounds approach.Until the 70-80's during the $20^{\text {th }}$, the National Council for Accreditation of Teacher Education (NCATE) revised the teacher education standards which need all the nation's teacher education institutions (Bear $80 \%$ of Teacher Education Project) the implementation of multicultural education in the curriculum and other aspects of reform and every country should make the multi-cultural teachers trailing as teacher's certificate prerequisite.

In all teacher education programs, teaching practice is considered the transition between professional preparation and practice, and it can assiste teachers linking the knowledge into tht more comprehensive education activities, get wisdom of practice and form implementation of teaching principles. It's the vital part of teaching program. Study shows that there is no special effect that pre-service teachers study multicultural education theory in the promotion of their different cultural backgrounds of students as well as the diversity of the teaching of critical reflective question. With regards to this, NCATE has announced that pre-service teachers will get the opportunities to access to minority.

Teachers should not confront different cultural students for the first time in their own classroom, instead of being trained during the college studying. Such training would greatly reduce the collision among the cultural contradictions in unfamiliar scene. New MCTE at practical experience and theoretical education strike a balance to explore a series of practical ways.

\section{Practical ways of education project among the primary and secondary school teachers}

\subsection{Field experiences}

Before prospective teachers becoming teachers, they have been requested to access to students from different cultural backgrounds, to practice in the classroom to gain the experiences and to be guided by professional teachers. The central target of field experiences is that implement and use of some pre-course knowledge and study methods, accumulate some experience and develop the teaching principles of students. They often worked by the timetable step by step, and assist co-operation teachers in achieving some tedious work at the most of time, such as examination and copying, etc. Field internships placed pre-service teacher in the diversification of the background, which cannot guarantee pre-service teachers to enhance multi-cultural theory into practice and deal with the real effect of diversity, for the reason is that in most cases the internship program and the teaching is usually adapted to school requirements or a particular class to limit the application of other methods, as well as practical teaching principles of personal development. Sometimes pre-service teachers are required to perform regular tasks, unable to experience the cultural background of the theory studying in the university curriculum, even though while studying at university they know the curriculum knowledge of multiculturalism, they are more concerned about how the classroom competent and have to stress the intrests of multicultural curriculum to obedy cooperation teachers' requirements. Pre-service teachers are more concerned about how to practice right, that is, how to follow the example of cooperation in the work of teachers in order to achieve the purpose of security clearance. They have no time to explore and consider, just play time until they really start teaching in 
accordance with their own worldview. This suppressed the students for the study of multicultural education.

Why does the field experences lack of attention and discussion about multicultural education? Why does multicultural education including social justice be short of critical thinking? There are several reasons for this emphasis:

One: before beginning internships, students lack of knowledge about multicultural education and experience, such as shortage of observation and consider the opportunities in multicultural education, short of implementate and test their knowledge opportunity in this area. For these reasons, some of the students usually have a different understanding about the meaning, for example, some people think that multicultural education is just the style of teaching containing a number of multi-cultural curriculum, but some people considered that it is how to regard people's relationship, in this case, their teaching and practice are limited in studying, acceptance and tolerance of different cultures to neglect of cultural pluralism, equality and the pursuit and explore of social justice, others also think that multicultures are not related with their own students and the curriculum is not important, so there is no need to explore social justice and cultural diversity issues.

The other: during practicing very few people take the risk to point out the existence of inequality and discrimination in the current society, the school policy and practice. Since some people are not aware, there is no reflection of their ideas. Some people are afraid of their own status and prestige endanged or damaged because of the opinion's proposing, even if someone has raised, they also have no idea how to put these terms or opinion into action, while it is often useless by translating into action because they can not get the support of other colleagues. The practitioner will feel evenmore helpness in this regard because they are only training, similar to visitors, received monitoring and limiting by co-operation teachers and education managers.

In short, because of the lack of knowledge and life experience, lack of time and the courage to challenge the status quo in schools, future teachers' understanding of multicultural education is affected.

\subsection{Service learning}

Over the past decade, at some schools and colleges in the United States, the new attachment methods service learning has aroused great concern by increasing students' practical experience, improving understanding and awareness of society. The service can be seen as the principle of education and a teaching method, as an educational principle, it can help students develop their personality and promote social responsibility, so it is a form of civic education in democratic society; as a teaching method, the service learning put service activity and academic curriculum together, so that students recognize the really demands of the community by actual activities and reflective knowledge. We can know that the purpose of service learning on the multi-cultural background are sure of diversity, criticize inequality and set up new communities, otherwise, it also gives teachers the opportunities of familiar with the cultural diversity, recognize the significance and value of cultural diversity.

Service learning requires students to voluntaryly ensure the minimum 12 hours' exchanges with students from different cultural backgrounds at the center of city schools, then according to their own experiences to write a reflection report to make students learn from each other and communicate their experiences, expand horizons and understand the diversity. The purpose of this internship experience is to change and challenge the original single world view of students, right to design and implement service learning activities, and to provide opportunities for strengthening the academic knowledge, teaching skills and individual development on the basis of solving the above problems. Service learning is also a way of pre-service teachers' understanding learner's experience, and the cross-cultural experience directly can help them re-consider the stenosing of relevant standards which often cause misunderstanding between teachers and students, but there are also the following questions:

One: service learning was seen as acts of love. Its center is the meaning of the provision of help, while there is an obligation to donors and it is a charity to a disadvantaged people rather than understand and study the diversity of society through such services. But learn through the service or put people of color living in poverty as a sick person, rather than knowledge resources. Therefore, it usually makes different distances between providers and recipients by providing the privileges or belittling the recipient, with the opposite goal of multicultural education.

Two: service learning was seen as civic education. It conveys that service learning can cultivate citizens and promote student's gainning the knowledge and skills of social awareness and civic responsibility's requirement. This opinion firmly believes that service operations help to cultivate good teachers and they can recognize that low-income groups and different social groups of people facing difficulties when students take part in service learning activities. But they rarely put the question into the right to analysis on the background of this broad. Not 
questioned to no rights, no right to challenge and empower, and did not address structural inequality, thus it undermine the recognize to the purpose of multicultural education.

Three: Some teachers feel that teacher education curriculum has been very cumbersome, and there is the difficulty of arranging for K-12 schools and community sites, on the other hand, there exist obstacles linked the service to national teacher education accreditation standards.

Reflection interns report also confirms the above opinion, interns must really exist on the extent of rescue from the mentality of the poor and think that they made an important contribution to the community. Although these experiences make students insight into the students school life from different cultural, many students on the stereotype to some groups have not changed. Consequently, through the study of the way, the service has provided the opportunities of studying "the Other" culture by a practical way and multicultural education can become the abstract into a reality (Boyle-Baise 2002). But at the same time we also see that it is not enough to really study cultural diversity only by studying the form of service to enable pre-service teachers to deal with students from different cultural backgrounds.

\subsection{Realistic approach}

Learning is happened among the action, the scenes and the function of culture, that is, the meaningful learning is generated through situated. How to make the adoption of pre-service teachers to engage in meaningful exchanges with children from different cultural and social background to ensure that they are able to explore the more selective topic and experience the multi-cultural of the real scene? Some scholars have suggested the use of realistic ways. In recent years, "the basic and secondary education students" curriculums was offered at major state universities in the southern United States, which syllabus requirements is that teachers must understand the diversity of the current class for preparation to teach every student in today or tomorrow's schools. In another way, Curriculum must integrate with practice from teacher-centered to train, when each pre-service teachers in order to finish the entire curriculum must in charge of semester students learning English and be responsible for the exchange between their students and their parents, while the teachers can research different students' cultures to combine the theory and practice by a new perspective of the existence question of pluralism, and then the missions are undertaken by the exchanges with the students and the experience made in the process of homework, at last they get credit.

Realistic approach do not begin in teaching the theory in the classroom instead of the real and meaningful practice and teachers should theoretical reflect and discuss such scenarios questions. It also begins from the experience and knowledge of the pre-service teachers not from the teaching and learning's objective theory. Korthagen (2001) point out that the practice of pre-service teachers is the effective beginning of school and superior to the theory from outside. In short, this method is an inductive method and pre-service teachers form their own opinion on the basis of the experiences and questions arising from a specific scenario. Brown (1989) also thinks that the knowledge gained by this way is considered as situated knowledge. The methods's opinion is that the study style of the several former researching for multi-cultural is the class discussion of the traditional textbooks, and then practice with completely out of the major content of study.

The steps in accordance with redesigning the realistic multi-cultural study according to the methods of realistic approach is following:

One: they are asked to write an article to clarify the standard preparation about the situation of facing the diversification learners before the pre-job training of teachers.

Two: former teachers need to make a follow-up survey of a student all the semester (take part in all their courses, breaks and lunch)

Three: former teachers need to pay a visit to all teachers contacting with their students. When staying with the student, teachers should take the initiative to look for educational topics.

Four: pre-service teacher are required to make a detailed record of the conversation with the student to obtain more detailed information.

Five: pre-service teachers should become better educator by visiting student's parents to obtain information.

Six: pre-service teachers should familiar with the culture of the student by researching.

Seven: the experience of multiculturalism, feelings, opinion and attitude should be summed up in accordance with the "Practice Week" writing by pre-service teachers.

In order to verify the effectiveness of this approach, Dario J Almarza and other people made a two-year follow-up study on the 240 female teachers (Its ethnic composition: Asian American1\%, Spain Asians 1\%, 
African American1\%, Buckra97\%). Studies show that students' reports at pre-internship states that students have been ready to teach a variety of students and be confident in putting their learning into practice. They believe themselves that they have been for a very sensitive issue of diversity and be able to know how to deal with any question in the classroom. Furthermore, the common reflection of students to the multi-cultural curriculum is that they have well-known these knowledge by the study of the curriculum. At the first two weeks of follow-up survey, most of students who assume themselves having prepared well experienced a cultural reality shock. Student teachers'disappointment is found in their weekly journals.

Students think themselves as being well aware of the requisite knowledge before internshipping, but the fact is that they do know nothing and have no idea about how to help their students, and they had a new understanding after that. At the beginning of track practice, pre-service teachers produce a sense of ownership to track students, and they called their responsible for students as "my child"during discussing in the classroom of the university. Such the style of calling not only address them during exploring the questions, but also express a relation of identity in the course of exchanges between pre-service teachers and students. The identity makes teachers to deconstruct and constuct the significance of their previous multiculturalism.

Students will be able to understand more deeply multiculturalism by the use of methods, and the more important thing is getting the opportunities of their individual growth, knowing their own identity and culture and knowing how to better educate students from different cultural backgrounds. The implementation of this approach is for learning multiculturalism by practice and "my child"instead of studing the theory by textbooks and examinations.

More and more attention to realistic approaches, training are shifting from conventional mission to real classroom scenarios, in which former teachers will form their own knowledge to generate individual learning needs and focus on exploring behavior as the center of learning. What's more, because it will make efforts to diversify education since pre-service teachers put their position on students called as my child, this methods play an active role on the understanding of multiculturalism and the ability to link practice and theory.

As to compare the attachment methods above, primary and secondary school teachers training on the multi-cultural background in any forms should follow the principles:

One: some opportunities should be provided to teacher education such as making pre-service teachers experiencing linguistic diversity of practice.

Two: teacher training courses should add to some contents of reflecting on practice and discussion so that pre-service teachers can know their own idea about multi-cultural perspective before they graduated.

Third: offer extensive, continuous and in-depth practical experience to make pre-service teachers profoundly understand cultural and linguistic diversity of students.

\section{Conclusion}

Teacher training is the most important part of educational planning, and by it teachers can get in the field of knowledge as well as other cross-cutting knowledge, so we can say thatanother key knowledge stems is wisdom of practice. In another way, training enable to provide pre-service teachers opportunities of practicing knowledge learning from classroom of university and also can make prospective teachers engage in multicultural education better to meet the challenges of the real world. In the United States, more and more and more states enact legislation to require indispensable for practice experiences in the situation of the different classroom in order to have teacher certification.

\section{References}

Allen, B. A. \& Boykin, A. W. (1992). African American children and the educational process: Alleviating cultural discontinuity through prescriptive pedagogy. School Psychology Review, 21(4), 586-596.

American Psychological Association. (2010). Publication manual of the American Psychological Association (6th ed.). Washington, DC: Author.

Banks, C. \& Banks, J. (1995). Equity pedagogy: An essential component of multicultural education, Theory into Practice, 34(3), 152-158.

Bell, Y. R. (1994). A culturally sensitive analysis of black learning styles. Journal of Black Psychology, 20(1), 47-61.

Day, F. (1994). Multicultural voices in contemporary literature: A resource for teachers. Portsmouth Heinemann.

Delgado-Gaitan, C. (1990). Literacy for Empowerment: The Role of Parents in Children's Education. New York: 
The Falmer Press.

Dyson, A. H. \& Genishi, C. (1990). The need for story: Cultural diversity in classroom and community,Urbana. National Council of Teachers of English.

Fradd, S.H. \& Weismantel, M.J. (1989). Meeting the Needs of culturally and linguistically different students: A handbook for educators. Boston: College-Hill Press.

Gay, G. (1987). Expressive ethos of African-American culture In G. Gay and W.L. Baber (eds.) Expressively Black: The cultural basis of ethnic identity. (pp. 1-16). New York: Praeger Publishers.

Gonzalez, V. \& Yawkey, T. (1997). Assessment and instruction of culturally and linguistically diverse students with or at-risk of learning problems. Needham Heights:. Allyn \& Bacon.

Hernandez, H. (1997). Teaching in Multilingual Classrooms: A teacher's guide to context, process, and content. Upper Saddle River: Prentice-Hall, Inc.

Howard, G. (1999). We can't teach what we don't know: White teachers, multiracial schools. New York Teacher's College Press.

Ladson, B. (1992). Liberatory consequences of literacy: A case of culturally relevant instruction for African American students. Journal of Negro Education, 61(3), 378-390.

Larke, P. J. (1992). Effective multicultural teachers: Meeting the challenges of diverse classrooms. Equity \& Excellence, 25(2-4), 133-138.

Nieto, S. (1996). Affirming diversity: The sociopolitical context of multicultural education, White Plains. Longman Publishers.

Takaki, R. (1993). In a different mirror: A history of multicultural America. New York: Little, Brown.

Wolk, S. (1998). A Democratic Classroom, Portsmouth. NH: Heinemann. 